\title{
REVIEW
}

\section{Virtual reality among children with mental disorders: A mini-review}

\author{
Marjan Rasoulian-Kasrineh ${ }^{1}$ Seyyed-Mohammad Tabatabaei $^{1,2,{ }^{*}}$ \\ ${ }^{1}$ Department of Medical Informatics, Faculty of Medicine, Mashhad University of Medical Sciences, Mashhad, Iran \\ ${ }^{2}$ Clinical Research Development Unit, Imam Reza Hospital, Mashhad University of Medical Sciences, Mashhad, Iran
}

\section{Check for updates}

Correspondence to: Seyyed-Mohammad Tabatabaei, Department of Medical Informatics, Faculty of Medicine, Mashhad University of Medical Sciences, Mashhad, Iran; E-mail: tabatabaeimh@ mums.ac.ir

Received: August 13, 2021;

Accepted: September 2, 2021;

Published: September 3, 2021.

Citation: Rasoulian-Kasrineh M and Tabatabaei SM Virtual reality among children with mental disorders: A mini-review. Adv Health Behav, 2021, 4(1): 177181. https://doi.org/10.25082/AHB.2021.01.004

Copyright: () 2021 Marjan Rasoulian-Kasrineh and Seyyed-Mohammad Tabatabaei. This is an open access article distributed under the terms of the Creative Commons Attribution License, which permits unrestricted use, distribution, and reproduction in any medium, provided the original author and source are credited.

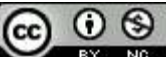

\begin{abstract}
Background: Mental disorders are a group of disorders that affect thinking and behavior by causing discomfort or disability to the person. Almost one in eight people aged 5 to 19 deals with these kinds of disorders and his or her growth may be significantly affected. It seems that using novel technologies in such cases are helpful. One of these advanced technologies, which has recently attracted a lot of attention in many fields such as health, is Virtual Reality. Therefore, the present study aimed to provide a brief review about the use of Virtual Reality among children with mental disorders. Methods: In this study, articles in which Virtual Reality were used among children dealing with mental disorders published during 2012 to 2021 were investigated. Electronic databases such as PsycINFO, Pubmed, Google Scholar and Medline were searched. Results: Children deal with different types of mental disorders and Virtual Reality has been used for many of them. The most common of them, in which Virtual Reality have been used and caused improvements include Attention Deficit Hyperactivity Disorder, Anxiety Disorder, Conduct Disorder, Autism Spectrum Disorder, Depressive Disorder, Schizophrenia Disorder, and Developmental Disability. Discussion and conclusion: According to the results, Virtual Reality is a very interesting, useful, effective and safe technology for patients dealing with mental disorders especially children and adolescence. It is actually a highly specialized technology which can provide improvement, and in some cases completely new ways of treatment for children suffering from mental disorders.
\end{abstract}

Keywords: mental disorders, virtual reality, children

\section{Introduction}

Mental disorders are a group of disorders that affect thinking and behavior by causing discomfort or disability to the person [1]. Mental disorders are very common among children and adolescents since almost one in eight aged 5 to 19 deals with it and it may have a significant impact on his or her growth [2]. Moreover, these kinds of disorders also affect children's performance in schools and their ability to interact with other children and adults. If mental disorders are not treated quickly, they will be so destructive in the growth process that affects them for the rest of their lives [1].

It seems that using novel technologies in such cases is required [5]. One of these advanced technologies, which has recently attracted a lot of attention in many fields such as health, is Virtual Reality (VR). VR is based on a three-dimensional world created by computers so that one can move and interact with which makes him feel that he is really there $[6,7]$. VR-based interventions are increasingly being considered as innovative choices to help patients with motor abnormalities, cognitive, mental, and functional disorders. For example, in the case of anxiety-related problems, it can give patients the opportunity to re-evaluate their fears, try out new treatment strategies, and get new knowledge which may help them to present in the real world $[4,8,9]$.

Using a virtual environment, this technology tries to change the function of brain and its inference process and somehow deceive it to achieve its desired goal [7]. Considering the speed of these emerging technologies advancement, it seems necessary for health professionals, policy makers and parents to know better about using VR among children with mental disorders so that they can use it. Therefore, the present study aimed to provide a brief review about the use of virtual reality among children with mental disorders. 


\section{Methods}

In this study, articles in which virtual reality were used among children with disorders published during 2012 to 2021 were investigated. Electronic databases such as PsycINFO, Pubmed, Google Scholar and Medline were searched to identify these articles using the keywords Psychiatric Disorders, Mental Disorders, Virtual Reality, Anxiety Disorder, Conduct Disorder, Autism Spectrum Disorders, Depressive Disorders Developmental Disability, Schizophrenia and Attention Deficit Hyperactivity Disorder and Children.

\section{Results}

There are different types of mental disorders in children, each of which has different symptoms and causes. In this section, some of the most common mental disorders in children that have been improved by using virtual reality will be discussed.

\subsection{Attention Deficit Hyperactivity Disorder (ADHD)}

It is a neurodevelopmental disorder that dates back to childhood and its symptoms include Attention Deficit Disorder, Impulsivity, and Hyperactivity [10]. VR-based interventions for the treatment of hyperactivity among children indicate to be effective and also it is attractive for them [11-14]. The important point mentioned in the studies is that this type of intervention has no negative side effects [15].

\subsection{Anxiety disorder}

Anxiety disorders, which are known as the most common disorders in the field of psychiatry, are an uncontrollable state with feelings of tension, irritability, restless sleep, negative thoughts and physiological changes such as increased pressure and gastrointestinal disturbances $[16,17]$ Studies showed that the VR-based interventions are effective in order to treat phobias, especially in the field of speech [18-22]. However, in a study it was stated that it did not cause any changes in the speech length criterion [18].

\subsection{Conduct disorder}

It is a disruptive behavioral disorder which comes from a persistent pattern of behavior in which the basic rights of others and age-appropriate social norms are ignored by a child or an adolescent. The disorder often includes premature sexual activity, persistent physical or verbal contacts, emotional outbursts, recklessness, antisocial behavior, and low self-esteem [23]. Interventions with the aim of evaluating this type of disorder using VR-based solutions have been reported to be effective [23-25].

\subsection{Autism Spectrum Disorder (ASD)}

ASD is a neurodevelopmental disorder which is unfortunately spreading rapidly. This disorder causes impairment in interactions as well as social relationships, difficulty in perception processing and also repetitive behaviors [26]. Many studies have been conducted in this field which have proven the usefulness of VR-based interventions in patient empowerment [27-29].

\subsection{Depressive disorder}

Depressive disorder is a common but serious mood disorder affecting how one feels, thinks and even control his/her daily activities, such as sleeping, eating or working. The use of virtual reality applications has been proven to be effective in reducing the severity of such disorders $[30,31]$.

\subsection{Schizophrenia disorder}

Schizophrenia is a severe and debilitating brain and behavior disorder that involves symptoms, such as hallucinations, delusions, disorganized thoughts, and cognitive deficits, with a lifetime prevalence of approximately 1\% [32]. Studies used VR-based interventions among patients with schizophrenia have shown promising results in maintaining and even improving interpersonal social skills, as well as reducing auditory hallucinations and paranoia [33,34]. It is noteworthy 
that patients have stated that the use of VR has provided them a pleasurable treatment and has make them more motivated. So, the combination of using VR-based treatment along with conventional treatment can have significant and lasting benefits that may have a great impact on the quality of life of patients $[35,36]$.

\subsection{Developmental disability}

Developmental disorders are defined as failure to meet expected developmental milestones in one or more areas including physical, social, emotional, intellectual, language / speech, and adaptive behavior $[37,38]$. Although few studies have been conducted on the field of using VR among these patients, they resulted that their treatment were improved [39-41].

\section{Discussion and conclusion}

This aim of the current study was to investigate the application of VR among children dealing with mental disorders. The results showed that VR has been clearly effective among patients dealing with mental disorders especially children and adolescence. VR is a highly specialized technology which can provide improvement, and in some cases completely new ways of treatment for children suffering from mental disorders [33].

Although VR needs expensive equipment, it is somehow easy to use, therefore it can be used by any one at any time in any place which would help patient to get involve in their treatment and provide self-care among the community [42]. In fact, VR can be useful in empowering the patient, controlling and treating the disease by helping the patient or his/her family. This becomes even more important when we recall the current situation we are facing due to COVID-19, because using such technologies may reduce medical contacts and helps control the pandemic.

According to the investigated studies, using VR as a supplementary tool in order to improve education, empowerment, treatment and prevention in the health domain, especially in the field of mental disorders, is increasing day by day. Actually, VR provides an effective ability to assess, understand and treat mental health problems. Also, considering the expanding use of portable smart devices, especially mobile phones and tablets, and their abilities, VR-based applications and games which are designed for them, will become even more effective and practical, and it is predicted that to be even more popular in the future.

\section{Acknowledgements}

We would like to thank Clinical Research Development Unit, Imam Reza Hospital, Mashhad University of Medical Sciences, for their assistance.

\section{Conflict of interest}

The authors declare no conflict of interest.

\section{Author contributions}

The two authors passed four criteria for authorship contribution based on the recommendations of the International Committee of Medical Journal Editor.

\section{References}

[1] Vasileva M, Graf RK, Reinelt T, et al. Research review: A meta-analysis of the international prevalence and comorbidity of mental disorders in children between 1 and 7 years. Journal of Child Psychology and Psychiatry, 2021, 62(4): 372-381. https://doi.org/10.1111/jcpp.13261

[2] Halldorsson B, Hill C, Waite P, et al. Annual Research Review: Immersive virtual reality and digital applied gaming interventions for the treatment of mental health problems in children and young people: the need for rigorous treatment development and clinical evaluation. Journal of Child Psychology and Psychiatry, 2021, 62(5): 584-605.

https://doi.org/10.1111/jcpp.13400 
[3] Botting N, Powls A, Cooke RW, et al. Attention deficit hyperactivity disorders and other psychiatric outcomes in very low birthweight children at 12 years. Journal of Child Psychology and Psychiatry, 1997, 38(8): 931-941. https://doi.org/10.1111/j.1469-7610.1997.tb01612.x

[4] Sarraf-Razavi M, Tabatabaei SM, Talaei A, et al. Application of Virtual Reality for Helping People with Psychiatric Disorders: A Mini Review. Landscape, 2019, 109(3): 395-417.

[5] Burke SM. The Use of Technology by Adolescents With Intellectual and Developmental Disabilities. Journal of pediatric nursing, 2017, 37: 134-135. https://doi.org/10.1016/j.pedn.2017.06.019

[6] Donath L, Rössler R and Faude O. Effects of virtual reality training (exergaming) compared to alternative exercise training and passive control on standing balance and functional mobility in healthy community-dwelling seniors: a meta-analytical review. Sports medicine, 2016, 46(9): 1293 1309. https://doi.org/10.1007/s40279-016-0485-1

[7] Tabatabaei M and Talaei A. Virtual Reality as a Friend of the Elderly: A Mini-Review. Biomedical Journal of Scientific \& Technical Research, 2019, 22(2): 16517-16519. https://doi.org/10.26717/BJSTR.2019.22.003723

[8] Aziz HA. Virtual reality programs applications in healthcare. Journal of Health \& Medical Informatics, 2018, 9(1): 305 . https://doi.org/10.4172/2157-7420.1000305

[9] Rizzo A, Thomas Koenig S and Talbot TB. Clinical results using virtual reality. Journal of Technology in Human Services, 2019, 37(1): 51-74. https://doi.org/10.1080/15228835.2019.1604292

[10] Cortese S, Panei P, Arcieri R, et al. Safety of methylphenidate and atomoxetine in children with attention-deficit/hyperactivity disorder (ADHD): data from the Italian National ADHD Registry. CNS drugs, 2015, 29(10): 865-877. https://doi.org/10.1007/s40263-015-0266-7

[11] Eom H, Kim K, Lee S, et al. Development of virtual reality continuous performance test utilizing social cues for children and adolescents with attention-deficit/hyperactivity disorder. Cyberpsychology, Behavior, and Social Networking, 2019, 22(3): 198-204. https://doi.org/10.1089/cyber.2018.0377

[12] Fang Y and Dai Han HL. A virtual reality application for assessment for attention deficit hyperactivity disorder in school-aged children. Neuropsychiatric Disease and Treatment, 2019, 15: 1517. https://doi.org/10.2147/NDT.S206742

[13] Laws G, Briscoe J, Ang S, et al. Child neuropsychology: a journal on normal and abnormal development in childhood and adolescence. Child Neuropsychology: A Journal on Normal and Abnormal Development in Childhood and Adolescence, 2014.

[14] Rodríguez C, Areces D, García T, et al. Comparison between two continuous performance tests for identifying ADHD: Traditional vs. virtual reality. International Journal of Clinical and Health Psychology, 2018, 18(3): 254-263. https://doi.org/10.1016/j.ijchp.2018.06.003

[15] Parsons TD, Duffield T and Asbee J. A comparison of virtual reality classroom continuous performance tests to traditional continuous performance tests in delineating ADHD: a meta-analysis. Neuropsychology Review, 2019, 29(3): 338-356. https://doi.org/10.1007/s11065-019-09407-6

[16] Bandelow B, Michaelis S and Wedekind D. Treatment of anxiety disorders. Dialogues in Clinical Neuroscience, 2017, 19(2): 93. https://doi.org/10.31887/DCNS.2017.19.2/bbandelow

[17] Ströhle A, Gensichen J and Domschke K. The diagnosis and treatment of anxiety disorders. Deutsches Ärzteblatt International, 2018, 115(37): 611. https://doi.org/10.3238/arztebl.2018.0611

[18] Anderson PL, Edwards SM and Goodnight JR. Virtual reality and exposure group therapy for social anxiety disorder: Results from a 4-6 year follow-up. Cognitive Therapy and Research, 2017, 41(2): 230-236. https://doi.org/10.1007/s10608-016-9820-y

[19] Bouchard S, Dumoulin S, Robillard G, et al. Virtual reality compared with in vivo exposure in the treatment of social anxiety disorder: a three-arm randomised controlled trial. The British Journal of Psychiatry, 2017, 210(4): 276-283. https://doi.org/10.1192/bjp.bp.116.184234

[20] Cieślik B, Mazurek J, Rutkowski S, et al. Virtual reality in psychiatric disorders: A systematic review of reviews. Complementary Therapies in Medicine, 2020, 52: 102480 https://doi.org/10.1016/j.ctim.2020.102480

[21] Maples-Keller JL, Yasinski C, Manjin N, et al. Virtual reality-enhanced extinction of phobias and post-traumatic stress. Neurotherapeutics, 2017, 14(3): 554-563. https://doi.org/10.1007/s13311-017-0534-y

[22] Owens ME and Beidel DC. Can virtual reality effectively elicit distress associated with social anxiety disorder? Journal of Psychopathology and Behavioral Assessment, 2015, 37(2): 296-305. https://doi.org/10.1007/s10862-014-9454-x

[23] Van Loon A, Bailenson J, Zaki J, et al. Virtual reality perspective-taking increases cognitive empathy for specific others. PloS One, 2018, 13(8): e0202442. https://doi.org/10.1371/journal.pone.0202442 
[24] Alsem SC, van Dijk A, Verhulp EE, et al. Using virtual reality to treat aggressive behavior problems in children: A feasibility study. Clinical Child Psychology and Psychiatry, 2021: 13591045211026160. https://doi.org/10.1177/13591045211026160

[25] Dixon DR, Miyake CJ, Nohelty K, et al. Evaluation of an immersive virtual reality safety training used to teach pedestrian skills to children with autism spectrum disorder. Behavior Analysis in Practice, 2019: 1-10.

https://doi.org/10.1007/s40617-019-00401-1

[26] $\mathrm{Hu}$ T, Dong Y, He C, et al. The gut microbiota and oxidative stress in autism spectrum disorders (ASD). Oxidative Medicine and Cellular Longevity, 2020. https://doi.org/10.1155/2020/8396708

[27] Ghanouni P, Jarus T, Zwicker JG, et al. Social stories for children with autism spectrum disorder: Validating the content of a virtual reality program. Journal of Autism and Developmental Disorders, 2019, 49(2): 660-668. https://doi.org/10.1007/s10803-018-3737-0

[28] Ip HH, Wong SW, Chan DF, et al. Enhance emotional and social adaptation skills for children with autism spectrum disorder: A virtual reality enabled approach. Computers \& Education, 2018, 117: $1-15$. https://doi.org/10.1016/j.compedu.2017.09.010

[29] Lorenzo G, Lledó A, Pomares J, et al. Design and application of an immersive virtual reality system to enhance emotional skills for children with autism spectrum disorders. Computers \& Education, 2016, 98: 192-205. https://doi.org/10.1016/j.compedu.2016.03.018

[30] Li WH, Chung JO and Ho EK. The effectiveness of therapeutic play, using virtual reality computer games, in promoting the psychological well-being of children hospitalised with cancer. Journal of Clinical Nursing, 2011, 20(15-16): 2135-2143. https://doi.org/10.1111/j.1365-2702.2011.03733.x

[31] Lin AJ, Cheng F and Chen CB. (Editors). Use of virtual reality games in people with depression and anxiety. Proceedings of the 5th International Conference on Multimedia and Image Processing, 2020. https://doi.org/10.1145/3381271.3381299

[32] Gottesman II. Schizophrenia genesis: The origins of madness: WH Freeman/Times Books/Henry Holt \& Co, 1991.

[33] Park MJ, Kim DJ, Lee U, et al. A literature overview of virtual reality (VR) in treatment of psychiatric disorders: recent advances and limitations. Frontiers in Psychiatry, 2019, 10: 505. https://doi.org/10.3389/fpsyt.2019.00505

[34] Rus-Calafell M, Gutiérrez-Maldonado J and Ribas-Sabaté J. A virtual reality-integrated program for improving social skills in patients with schizophrenia: a pilot study. Journal of Behavior Therapy and Experimental Psychiatry, 2014, 45(1): 81-89. https://doi.org/10.1016/j.jbtep.2013.09.002

[35] du Sert OP, Potvin S, Lipp O, et al. Virtual reality therapy for refractory auditory verbal hallucinations in schizophrenia: a pilot clinical trial. Schizophrenia Research, 2018, 197: 176-181. https://doi.org/10.1016/j.schres.2018.02.031

[36] Rus-Calafell M, Garety P, Sason E, et al. Virtual reality in the assessment and treatment of psychosis: a systematic review of its utility, acceptability and effectiveness. Psychological Medicine, 2018, 48(3): 362-391. https://doi.org/10.1017/S0033291717001945

[37] Zablotsky B, Black LI and Blumberg SJ. Estimated prevalence of children with diagnosed developmental disabilities in the United States (2014-2016), 2017.

[38] Zablotsky B, Black LI, Maenner MJ, et al. Prevalence and trends of developmental disabilities among children in the United States: 2009-2017. Pediatrics, 2019, 144(4): e20190811. https://doi.org/10.1542/peds.2019-0811

[39] Gelsomini M, Garzotto F, Montesano D, et al. Wildcard: A wearable virtual reality storytelling tool for children with intellectual developmental disability. 2016 38th Annual International Conference of the IEEE Engineering in Medicine and Biology Society (EMBC), IEEE, 2016. https://doi.org/10.1109/EMBC.2016.7591896

[40] Krysta K, Krzystanek M, Cubała WJ, et al. Telepsychiatry and virtual reality in the treatment of patients with intellectual and developmental disabilities. Psychiatria Danubina, 2017, 29(3): 656-659.

[41] Muneer R, Saxena T and Karanth P. Virtual reality games as an intervention for children: A pilot study. Disability, CBR \& Inclusive Development, 2015, 26(3): 77-96. https://doi.org/10.5463/dcid.v26i3.456

[42] Atasavun Uysal S and Baltaci G. Effects of Nintendo Wii ${ }^{T M}$ training on occupational performance, balance, and daily living activities in children with spastic hemiplegic cerebral palsy: A single-blind and randomized trial. Games for Health Journal, 2016, 5(5): 311-317. https://doi.org/10.1089/g4h.2015.0102 